\title{
Mitochondrial Haplotype-Based Identification of Ethanol-Preserved Root-Knot Nematodes from Africa
}

\author{
Chris Pagan, Danny Coyne, Regina Carneiro, George Kariuki, Nessie Luambano, \\ Antoine Affokpon, and Valerie M. Williamson
}

First and seventh authors: Department of Plant Pathology, University of California, Davis; second author: International Institute of Tropical Agriculture (IITA), c/o icipe, Kasarani, P.O. Box 30772-00100, Nairobi, Kenya; third author: EMBRAPA-Recursos Genéticos e Biotecnologia, C. P. 02372, 70849-979 Brasilia, DF, Brazil; fourth author: Department of Agricultural Science and Technology, Kenyatta University, Nairobi, Kenya; fifth author: Sugar Cane Research Institute, PO Box 30031, Kibaha, Coast, Tanzania; and sixth author: Faculté des Sciences et Techniques de Dassa (FAST/Dassa), Université d'Abomey-Calavi (UAC), BP14, Dassa, Benin. Accepted for publication 20 September 2014.

\section{ABSTRACT}

Pagan, C., Coyne, D., Carneiro, R., Kariuki, G., Luambana, N., Affokpon, A., and Williamson, V. M. 2015. Mitochondrial haplotype-based identification of ethanol-preserved root-knot nematodes from Africa. Phytopathology 105:350-357.

The asexual root-knot nematodes (RKNs) (Meloidogyne spp.) exemplified by Meloidogyne incognita are widespread and damaging pests in tropical and subtropical regions worldwide. Comparison of amplification products of two adjacent polymorphic regions of the mitochondrial genome using DNA extracts of characterized RKN strains, including 15 different species, indicate that several species are derived from the same or closely related female lineages. Nevertheless, $M$. javanica, $M$. enterolobii, $M$. incognita, and other key species could each be assigned unique mitochondrial haplotypes based on polymerase chain reaction fragment size and restriction cleavage patterns. $M$. arenaria isolates did not group as a single haplotype, consistent with other reports of diversity within this species. To test the utility of this assay, we characterized ethanol-preserved samples from 103 single-species isolates from four countries in sub-Saharan Africa (Benin, Nigeria, Kenya, and Tanzania). Mitochondrial haplotypes corresponding to $M$. javanica and $M$. incognita were the most prevalent. Samples from western Africa included several instances of $M$. enterolobii but this species was not detected in samples from East Africa. This protocol provides progress toward a standardized strategy for identification of RKN species from small, preserved samples and a rational starting point for classifying species present in regions where previous knowledge has been limited.
Root-knot nematodes (RKNs) (Meloiodgyne spp.) are globally distributed pests that cause substantial economic damage to crops worldwide $(21,35,49)$. Most species associated with crops in tropical agriculture belong to a closely related, asexually reproducing (apomictic) species complex including Meloidogyne incognita, M. javanica, and $M$. arenaria, which we refer to collectively as the $M$. incognita group (MIG) $(30,41)$. Although the host range of these species is exceptionally broad, there are differences between species. Therefore, accurate characterization of prevailing nematode populations is essential to efficiently employ management strategies such as host plant resistance, biological control, and crop rotation, which may be dependent on the nematode taxa present. Similarly, for quarantine determination, accurate species diagnosis is essential. Notably, reports of the highly pathogenic and invasive species $M$. enterolobii have increased recently due, in part, to its pathogenicity on hosts resistant to MIG species (15).

Although host range tests provide the most directly useful information for agricultural applications, these require a prohibitive amount of time, resources, and well-characterized host material. Species identification can also be based on morphological differences (43) and isozyme polymorphisms (22). However, these approaches are time consuming and labor intensive and require living or well-preserved specimens. DNA-based identification, mostly utilizing polymerase chain reaction (PCR)-

Corresponding author: V. M. Williamson;

E-mail address: vmwilliamson@ucdavis.edu

http://dx.doi.org/10.1094/PHYTO-08-14-0225-R

(C) 2015 The American Phytopathological Society based amplification, has improved our ability to identify and diagnose RKNs $(2,4)$. Specific primers that direct amplification of a genomic fragment only from a target species have been developed for several parthenogenetic RKN lineages. This approach can be useful but suffers from the limitation that a negative result could indicate either a failed reaction or that the nematode is a different species or variant.

The DNA sequence of ribosomal RNA (rDNA) genes has been useful for determining phylogenetic relationships and as a diagnostic tool for many organisms. Comparison of rDNA sequences has divided Meloidogyne spp. into three well-supported major clades, with clade I containing the polyphagous tropical species and clades II and III containing nematodes from more temperate climates $(26,28,48)$. However, whereas clade II and clade III species were well resolved, those in clade I, particularly the MIG species, remained unresolved because sequence differences of rDNA copies within an individual RKN showed greater diversity than between species. Comparisons of sequences of single-copy nuclear genes also fail to form phylogenetic lineages concordant with recognized species, leading to speculation that MIG species have reticulate origins; that is, they arose by hybridization of two sexual species, perhaps with a common parent, followed by loss of ability to reproduce sexually (33). In support of this, wholegenome sequence analysis of $M$. incognita has revealed that it carries two or three diverged copies of many genomic sequences $(1,34)$.

The mitochondrial genome, due to its uniparental inheritance, can circumvent some of the difficulties of differentiating hybrid, parthenogenetic lineages (25). In fact, the mitochondrial genome of apomictic RKNs has revealed a useful source of diagnostic markers. The mitochondrial DNA (mtDNA) between the cyto- 
chrome oxidase II (COII) and large subunit of rDNA carries a noncoding intergenic spacer in MIG RKN species (40). Length differences of the intergenic spacer and restriction fragment length polymorphisms (RFLPs) of this region were used to develop a PCR-based assay that could distinguish five major RKN species (39), and this assay has been extended to other species (4). Hugall et al. (27) also examined mitochondrial RFLP patterns and, using over 50 independent isolates from Australia, observed perfect correspondence of mtDNA polymorphisms with esterase phenotypes. A diagnostic strategy based on amplification of two mtDNA regions that, together, span the spacer and part of the adjacent large subunit (16S) rRNA (lrDNA) gene was developed (46) (Fig. 1). The size of the intergenic spacer and sequence polymorphisms in the lrDNA that were revealed following digestion with the restriction enzymes HinfI and $M n l$ I were used to assign haplotypes.

In practice, RKNs are often identified only to genus, especially from locations where resources for morphological or molecular analysis are limited or inaccessible. Plant yield reductions due to RKNs are a principal production constraint for small-holder farmers in tropical countries and directly responsible for widespread misuse of pesticides (32). RKNs also undermine staple crop production, causing significant losses to staple food crops such as maize and cassava across sub-Saharan Africa (SSA) $(6,20)$. Knowledge of the species present is limited and is needed for planning management strategies (38). Here, we present a protocol to extract DNA from single egg masses of ethanol-preserved samples. We demonstrate that this DNA can be routinely amplified using the two sets of mitochondrial primers and used to assign a mitochondrial haplotype. We test this strategy using unknown samples from several countries in SSA as a step toward improving our ability to routinely characterize RKN species, especially from areas where our knowledge is less complete.

\section{MATERIALS AND METHODS}

Nematode strains. Characterized strains of RKN species used in this work are listed in Table 1. Strains with the designation BR following species name were from Brazil and have been previously identified or described using esterase phenotypes (8), sequence-characterized amplified region markers $(18,19,42,47$, 53 ) or morphological approaches $(7,10,13)$. DNA of $M$. arenaria F was provided by L. Perfus-Barbeoch, INRA, Sophia, France and $M$. arenaria 03-1 was provided by J. Starr, Texas A\&M. DNA was extracted from these samples as previously described $(31,42)$.
Samples from Africa. Sampling of field-cultivated crops was undertaken in Benin, Kenya, Nigeria, and Tanzania between 2009 and 2012. Infected roots were observed for egg masses, which were individually removed, placed in individual wells, and allowed to hatch. When egg masses could not be easily observed, the roots were coarsely chopped and used to infect 3-week-old 'Moneymaker' tomato seedlings, grown in steam-sterilized soil in 1-liter pots. Upon maturity of the nematodes, egg masses were individually removed as above. To initiate pure species cultures, the juveniles (J2) from each single well were inoculated onto 3-week-old tomato Moneymaker seedlings grown in steamsterilized soil in 1-liter pots in the screenhouse in each respective country. Upon maturity of the nematodes, 5 to 10 egg masses were removed from tomato roots of each single-egg mass culture and placed separately in $95 \%$ ethanol $(1 \mathrm{ml})$ in a durable microfuge tube. Samples were shipped at ambient temperature then stored, upon receipt, at University of California, Davis at $-20^{\circ} \mathrm{C}$.

DNA extraction from ethanol-preserved samples. A single egg mass was transferred from ethanol to $5 \mathrm{ml}$ of Tris-EDTA buffer in a $60-\mathrm{mm}$ petri dish to hydrate for at least $15 \mathrm{~min}$. The egg mass was teased apart to release eggs and emerged J2s. For each extract, 5 to $10 \mathrm{~J} 2 \mathrm{~s}$ or 10 disrupted eggs from a single egg mass were transferred into $10 \mu \mathrm{l}$ of extraction buffer ( $10 \mathrm{mM}$ Tris, $1 \mathrm{mM}$ EDTA, $0.1 \%$ triton $\mathrm{X}$, and proteinase $\mathrm{K}$ [PCR grade, Fermentas] at $1 \mathrm{mg} / \mathrm{ml}$ ) and the nematodes were disrupted using a probe. Samples were frozen in $0.2-\mathrm{ml}$ PCR tubes at $-20^{\circ} \mathrm{C}$ overnight or longer. For extraction, samples were incubated at $56^{\circ} \mathrm{C}$ for $1 \mathrm{~h}$ followed by $95^{\circ} \mathrm{C}$ for $10 \mathrm{~min}$, then used immediately for PCR or stored at $-20^{\circ} \mathrm{C}$.

mtDNA analysis. mtDNA fragments were amplified using primer sets TRNAH (TGAATTTTTTATTGTGATTAA) and MRH106 (AATTTCTAAAGACTTTTCTTAGT) or MORF (ATC GGGGTTTAATAATGGG) and MTHIS (AAATTCAATTGAA ATTAATAGC) developed by Stanton et al. (46). DNA amplification by PCR was carried out using one unit per reaction of Amplitaq DNA polymerase (Applied Biosystems) with Buffer II supplied by the manufacturer. Amplification was carried out in a volume of $25 \mu \mathrm{l}$ with $0.5 \mu \mathrm{M}$ each primer; $0.2 \mathrm{mM}$ each dATP, dCTP, dGTP and dTTP; $3 \mathrm{mM} \mathrm{MgCl}_{2}$, and $1.5 \mu \mathrm{l}$ of DNA extract. Amplification conditions consisted of an initial denaturation at $94^{\circ} \mathrm{C}$ for $4 \mathrm{~min} ; 35$ cycles of $94^{\circ} \mathrm{C}$ for $30 \mathrm{~s}, 50^{\circ} \mathrm{C}$ for $30 \mathrm{~s}$, and $68^{\circ} \mathrm{C}$ for $60 \mathrm{~s}$; and a final extension at $68^{\circ} \mathrm{C}$ for $7 \mathrm{~min}$. DNA fragments were separated by electrophoresis in Tris-borate-EDTA buffer and $1.5 \%$ agarose gels containing GelRed (Biotium). Restriction enzymes HinfI and $M n l I$ were obtained from New England Biolabs and used as recommended by the manufacturer.

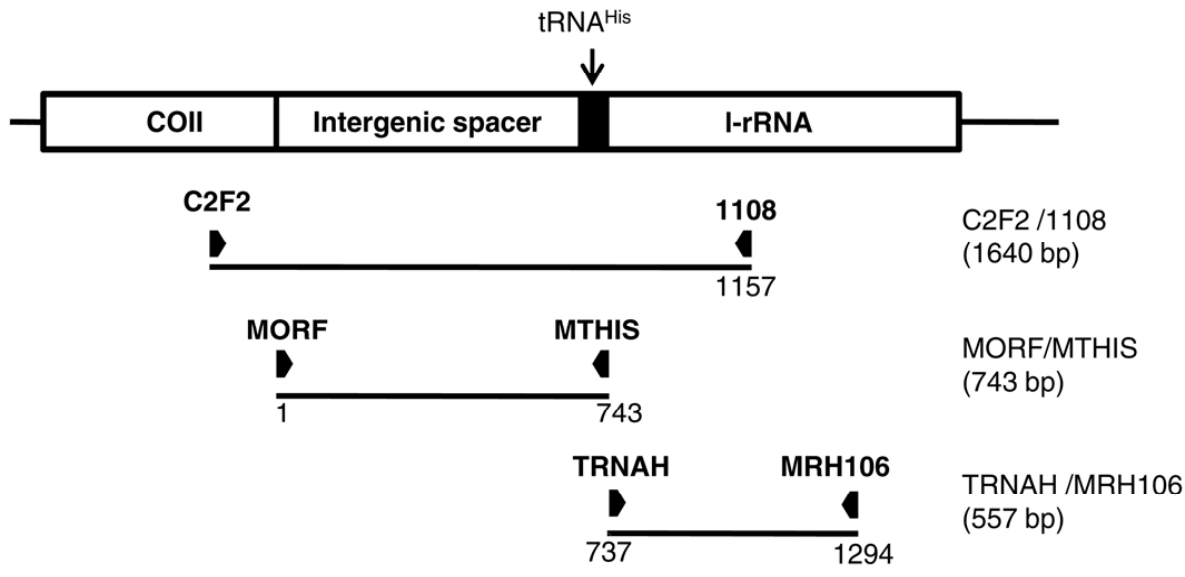

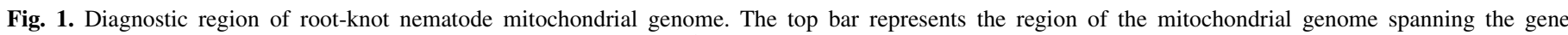
encoding cytochrome oxidase II (COII), the intergenic spacer, tRNA ${ }^{\text {His }}$, and the large subunit of the ribosomal RNA gene (l-rRNA). Position of the diagnostic DNA fragment amplified with primers C2F2 and 1108 (39) is shown below the bar. Below this are positions of fragments amplified with primer pairs MORF and MTHIS, and TRNAH and MRH106 (46). Numbers below fragments refer to positions in Meloidogyne javanica reference sequence (accession number L76261). 
Prior to sequencing, PCR products were treated using an EXoSAP-IT for PCR product Cleanup kit (Affymetrix). Sequencing was carried out by the DNA Sequencing Facility, College of Biological Sciences, University of California, Davis, with the same primers as used to generate the fragment.

\section{RESULTS}

Mitochondrial haplotype determination of characterized RKN. Primers TRNAH and MRH106 were used to amplify a 557-bp region of the mitochondrial genome, including part of the large subunit rRNA gene (Fig. 1). We amplified DNA from characterized RKN strains, including multiple isolates of the most common MIG species and additional species listed in Table 1. A fragment of $\approx 557 \mathrm{bp}$ was amplified from all tested strains except for $M$. enterolobii, which produced a fragment of $\approx 722$ bp (Fig. 2A; Table 1). DNA sequence of the amplified fragments from $M$. incognita, $M$. javanica, $M$. arenaria, and the other clade I species, except for $M$. enterolobii, showed high sequence similarity ( $>99 \%$ ) compared with the reference $M$. javanica sequence (L76261.1). M. enterolobii showed 87\% similarity to the reference sequence, and examination of the sequence revealed that the increased length was due to an insertion of $166 \mathrm{bp}$ adjacent to primer TRNAH. This same insertion was previously noted when $M$. enterolobii was amplified with primers $\mathrm{C} 2 \mathrm{~F} 2 / 1108$ and has been annotated as a tRNA ${ }^{\text {his }}$ gene (5). M. hapla, M. chitwoodi, and $M$. exigua sequence divergence from the $M$. javanica reference sequence was even greater $(87,80,72$, and $71 \%$ identity, respectively).

Comparison of the sequences of the amplified TRNAH/ MRH106 fragment from the MIG species (all clade I species in Table 1 except for $M$. enterolobii) revealed minor differences in length due to single-nucleotide insertions or deletions in a 150-bp tract of $100 \%$ AT in the large subunit of the ribosomal RNA gene (1-rRNA) gene; however, these length differences did not correlate with species. The remaining sequence differences correlated strongly with species and are summarized in Figure 3. Several of the sequence polymorphisms between MIG species affected cleavage sites for HinfI or MnlI, and cleavage of the amplification product with these enzymes allowed $M$. incognita, $M$. enterolobii, $M$. javanica, and M. hapla to be easily differentiated (Fig. 2B and $\mathrm{C}$; Table 1). For example, an A residue is present at position 1,182 in the reference $M$. javanica sequence and in both strains of $M$. javanica that we examined as well as in the reference sequence L76261.1. In all other MIG species, a G residue exists in this position, resulting in a cleavage site for the restriction enzyme HinfI. Due to an A residue at position 1,086, the M. izalcoensis fragment lacked an $M n l \mathrm{I}$ site and produced a novel digestion pattern. However, M. arabicida, M. ethiopica, M. hispanica, M. inornata, M. morocciensis, M. petunia, and M. paranaensis produced the same TRNAH/MRH106 cleavage pattern as $M$. arenaria and this group of species was not differentiated.

In an attempt to further differentiate MIG species, we amplified DNA extracts with primers MORF and MTHIS, which direct amplification of the intergenic spacer region (Fig. 1). These primers amplified a fragment from all the MIG species but not from other RKNs, including $M$. enterolobii. A fragment of $\approx 743 \mathrm{bp}$ was amplified from both strains of $M$. javanica tested as well as from $M$. incognita strains VW6, BR4, and BR6 (Fig. 2D; Table 1). However, $M$. incognita strain BR5 produced a shorter product $(\approx 636 \mathrm{bp})$. The amplification product from $M$. arenaria strain BR3 was 743 bp whereas those from $M$. arenaria strains F and 03-1 were only $214 \mathrm{bp}$ in length. DNA sequences of the amplified products from the two $M$. javanica strains were identical to each other and to the published $M$. javanica sequence (L76261.1, nucleotides 54 to 660). The corresponding regions from $M$. incognita strains VW6, BR4, and BR6 were identical to each other in sequence and differed by 8 nucleotides (nt) from L76261.1. These differences included the 6-nt changes reported by Stanton et al. (46) for Australian M. incognita isolates. The shorter length of the amplification product from $M$. incognita BR5 compared with the other $M$. incognita strains was due to two small deletions in the intergenic spacer (Fig. 4). M. arenaria strain BR3 amplified a 743-bp fragment that differed in $5 \mathrm{nt}$ from L76261.1, whereas the 214-bp amplification products from $M$. arenaria strains F and 03-1 were identical to each other in sequence and showed a deletion of $530 \mathrm{nt}$ within the intergenic region (Fig. 4). The MORF/MTHIS amplification product from

TABLE 1. Root knot nematode strains and their mitochondrial amplification products

\begin{tabular}{|c|c|c|c|c|c|c|c|}
\hline \multirow[b]{2}{*}{ Clade } & \multirow[b]{2}{*}{ Species, strain } & \multirow[b]{2}{*}{ Est $^{\mathrm{b}}$} & \multicolumn{3}{|c|}{ TRNAH/MRH106 fragment (bp) ${ }^{\mathrm{a}}$} & \multirow{2}{*}{$\begin{array}{c}\text { MORF/MTHIS } \\
\text { Fragment (bp) }\end{array}$} & \multirow[b]{2}{*}{ Host; geographical origin; source or reference } \\
\hline & & & Frag & HinfI dig & MnlI dig & & \\
\hline$\overline{\mathrm{I}}$ & Meloidogyne arenaria $\mathrm{G}$ & - & 557 & 445,112 & $340,140,77$ & 214 & Tomato; Guadeloupe; L. Perfus-Barbeoch, INRA \\
\hline $\mathrm{I}$ & M. arenaria $03-1$ & - & 557 & 445,112 & $340,140,77$ & 214 & Peanut; Texas; J. Starr, Texas A\&M \\
\hline I & M. arenaria $\mathrm{BR} 3$ & A2 & 557 & 445,112 & $340,140,77$ & 743 & Soybean; Ibituba, RS, Brazil; 16 \\
\hline I & M. enterolobii BR17 & E4 & 723 & 723 & 583,140 & NP & Guava; Petrolina, PR, Brazil; 48 \\
\hline I & M. enterolobii $\mathrm{CR}$ & - & 722 & 722 & 582,140 & NP & Guava; Costa Rica; 29 \\
\hline I & M. incognita BR4 & I1 & 557 & $396,112,49$ & 340,217 & 742 & Soybean; Londrina, PR, Brazil; 16 \\
\hline I & M. incognita BR5 & $\mathrm{I} 2$ & 557 & $396,112,49$ & 340,217 & 636 & Cotton; Umuarama, PR, Brazil; 44 \\
\hline I & M. incognita BR6 & $\mathrm{I} 2$ & 557 & $396,112,49$ & 340,217 & 742 & Cotton; Campo Verde, MT, Brazil; 44 \\
\hline $\mathrm{I}$ & M. incognita VW6 & - & 557 & $396,112,49$ & 340,217 & 742 & Cotton; California; 50 \\
\hline I & M. javanica VW4 & $\mathrm{J} 2$ & 558 & 558 & $341,140,77$ & 743 & Tomato; California; 52 \\
\hline $\mathrm{I}$ & M. javanica $\mathrm{BR} 1$ & $\mathrm{~J} 2$ & 558 & 558 & $341,140,77$ & 743 & Tomato; Brasília, DF, Brazil; 45 \\
\hline II & M. hapla VW9 & H1 & 556 & 446,110 & 556 & NP & Tomato; California; 31 \\
\hline II & M. hapla LM & - & 556 & 446,110 & 556 & NP & Unknown; La Mole, France; 50 \\
\hline II & M. hapla BR19 & $\mathrm{H} 1$ & 556 & 446,110 & 556 & NP & Strawberry; Botucatu, SP, Brazil; 11 \\
\hline I & M. arabicida BR14 & AR2 & 556 & 444,112 & $339,140,77$ & 789 & Coffee; Turialba, Costa Rica; 7 \\
\hline I & M. ethiopica BR 18 & E3 & 557 & 445,112 & $340,140,77$ & 742 & Kiwi; Farropilha, RS, Brazil; 14 \\
\hline I & M. hispanica $\mathrm{BR} 8$ & Hi3 & 559 & 447,112 & $342,140,77$ & 744 & Squash; Jacuipe, BA, Brazil; 9 \\
\hline I & M. inornata $\mathrm{BR} 9$ & $\mathrm{I} 3$ & 557 & 445,112 & $340,140,77$ & 742 & Yacon; Capão Bonito, SP, Brazil; 13 \\
\hline I & M. izalcoensis BR15 & $\mathrm{I} 4$ & 558 & 446,112 & 418,140 & 758 & Coffee; Izalco, El Salvador; 10 \\
\hline I & M. morocciensis BR7 & A3 & 558 & 446,112 & $341,140,77$ & 214 & Soybean; Santa Rosa, RS, Brazil; 16 \\
\hline I & M. paranaensis BR11 & $\mathrm{P} 1$ & 557 & 445,112 & $340,140,77$ & 425 & Coffee; Londrina, PR, Brazil; 7 \\
\hline I & M. paranaensis $\mathrm{BR} 12$ & $\mathrm{P} 2$ & 557 & 445,112 & $340,140,77$ & 425 & Coffee; Herculandia, SP, Brazil; 7 \\
\hline I & M. petunia $\mathrm{BR} 16$ & $\mathrm{Pe} 2$ & 557 & 445,112 & $340,140,77$ & 742 & Petunia; Riacho Fundo, DF, Brazil; 17 \\
\hline III & M. chitwoodi WAMC & - & 547 & 547 & 547 & NP & Potato; Washington; 36 \\
\hline III & M. exigua $\mathrm{BR} 13$ & E1 & 556 & 556 & 556 & NP & Coffee; Lavras, MG, Brazil; 37 \\
\hline
\end{tabular}

${ }^{a}$ Fragment sizes predicted from partial sequence and band sizes after gel electrophoresis; NP = no product or weak, nonspecific bands

${ }^{\mathrm{b}}$ Est $=$ esterase isozyme; $-=$ not available. 
M. morocciensis was $214 \mathrm{bp}$ in length and identical in sequence to that of $M$. arenaria strains $\mathrm{F}$ and 03-1. M. paranaensis also carried a deletion in the intergenic spacer compared with L76261.1. The MORF/MTHIS fragment of $M$. hispanica BR8 differed from L76261.1 by $15 \mathrm{nt}$ and was identical in sequence to the corresponding region in a previously reported sequence from $M$. hispanica (JN673274). Fragments amplified from M. inornata BR9, M. petunia BR16, and M. ethiopica BR18 were identical in sequence and differed by $5 \mathrm{nt}$ from L76261.1. MORF/MTHIS fragments amplified from $M$. izalcoensis and $M$. arabicida differed in length from 743 bp due to various insertions or deletions compared with M. javanica (Fig. 4).

Mitochondrial haplotype analysis of samples from Africa. Comparison of mtDNA fragments amplified in our study with those previously found (46) supported a robust key that separates the major tropical RKN species into mitochondrial haplotypes (Table 2). All $M$. javanica strains, and only strains of this species, produced a match for haplotype D. All M. incognita strains tested, with the exception of $M$. incognita BR5, and only $M$. incognita strains produced the haplotype B pattern. We refer to $M$. incognita BR5, which produced a shorter MORF/MTHIS fragment, as $M$. incognita variant 1 (V1) and the haplotype pattern as B'. Two of the three $M$. arenaria strains that we tested matched haplotype A and the third corresponded to haplotype G. Several additional
MIG species produced patterns corresponding to haplotype $\mathrm{G}$ and were not differentiated by this assay. The TRNAH/MRH106 pattern produced by $M$. enterolobii, which was not previously examined, was assigned haplotype K (Table 2).

To test the utility of the key in Table 2 for categorizing new isolates of RKNs, we prepared DNA extracts, each derived from a single egg mass, from 103 ethanol-preserved samples obtained from four countries in SSA. With primer set TRNAH/MRH106, an amplification product was obtained for all extracts tested. For 86 extracts, the product size was $\approx 556 \mathrm{nt}$ and, for the remaining extracts, the product was $\approx 723 \mathrm{bp}$, as expected for $M$. enterolobii. From some extracts small, less-intense bands were seen at $<100 \mathrm{bp}$ following amplification; therefore, haplotype assignments following digestion were based on consideration only of fragments $>100$ bp. Based on the sizes of the MnlI and HinfI digestion products of the TRNAH/MRH106 fragments and the presence and size of the MORF/MTHIS fragment, we were able to assign a haplotype to all but three isolates (Table 3). Two isolates, both from coastal region of Kenya (Mtwapa) on tomato, produced a haplotype B pattern for the TRNAH/MRH106 fragment following digestion with the $M n l I$ but a haplotype G pattern following HinfI digestion. DNA sequence of the amplified fragment showed that it differed from that of $M$. incognita by a single nucleotide, resulting in the loss of an HinfI site (H-790 in Fig. 2). One sample
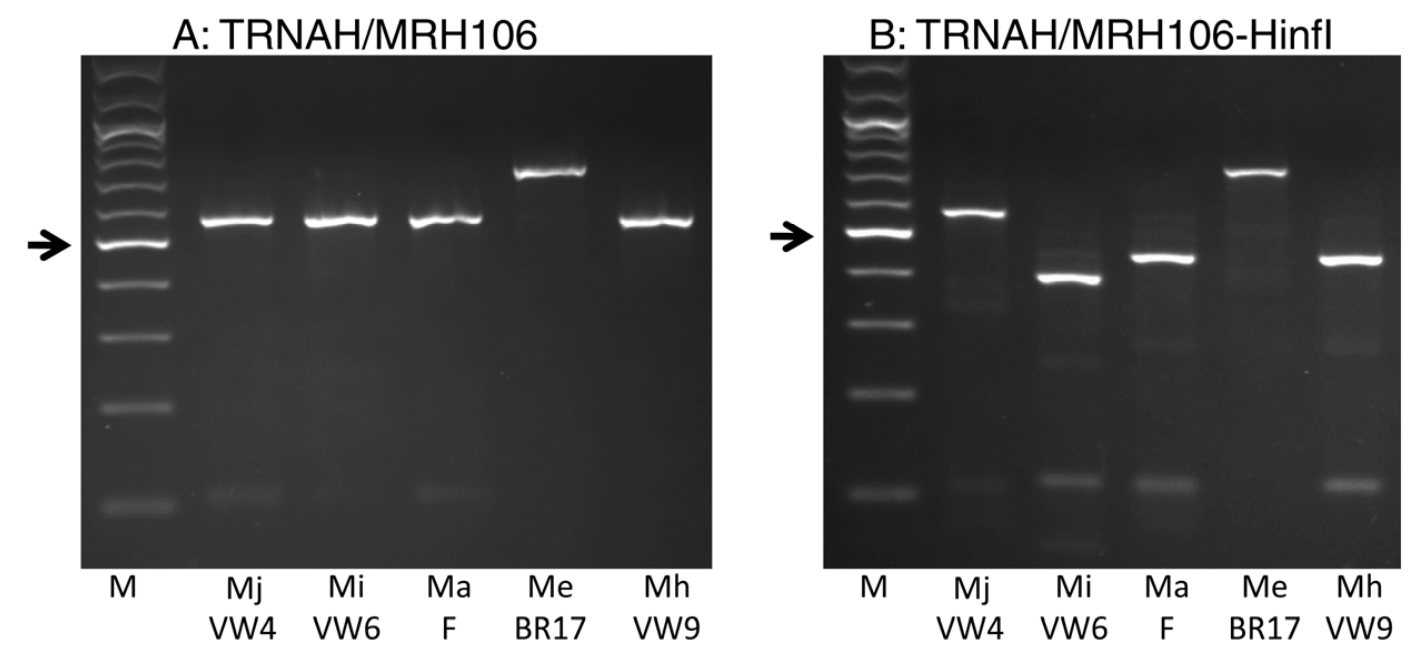

\section{C: TRNAH/MRH106- Mnll}
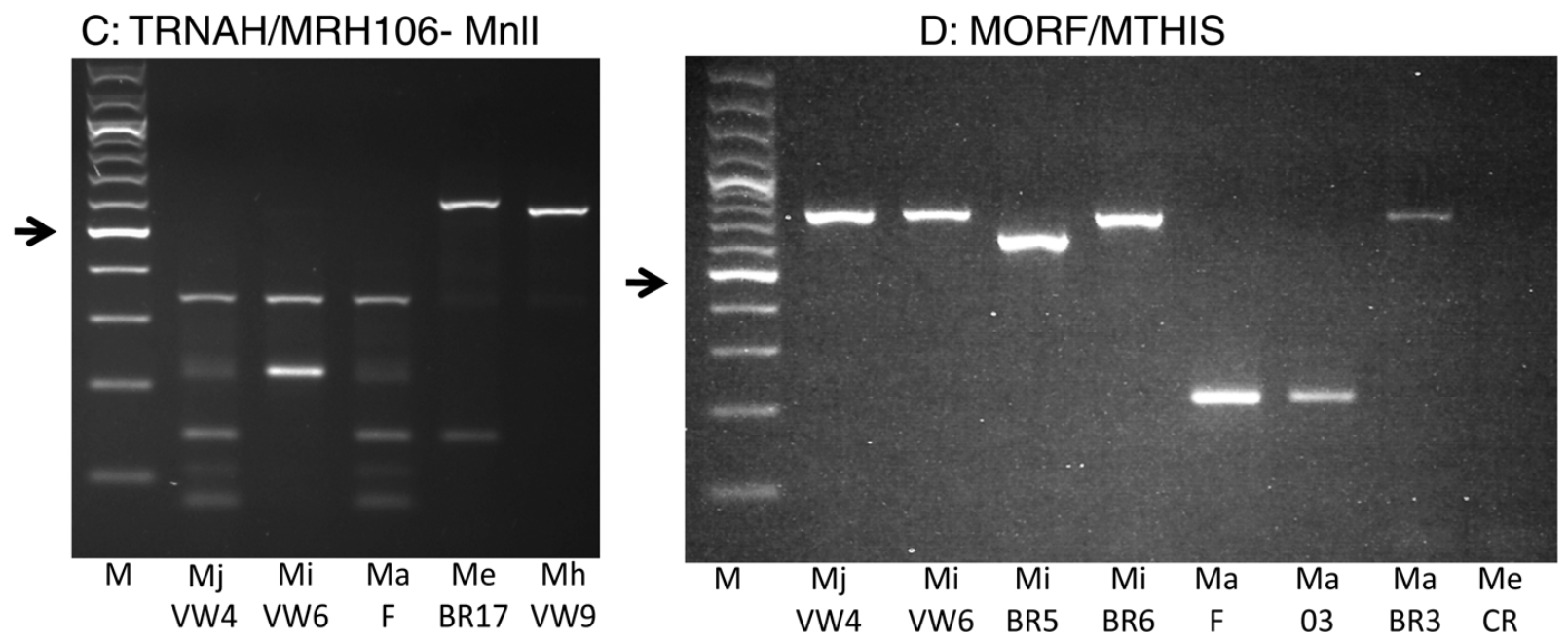

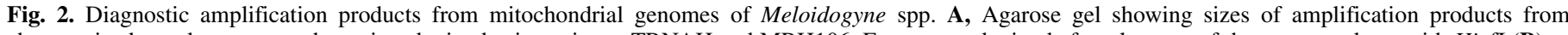

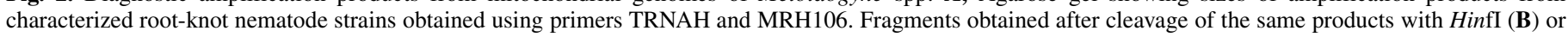

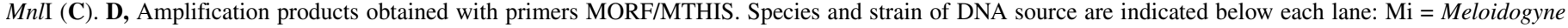

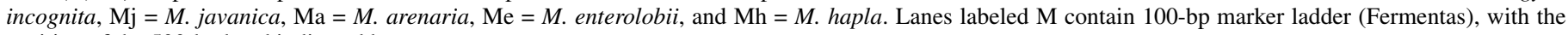
position of the 500-bp band indicated by an arrow. 
from Benin produced the TRNAH/MRH106 cleavage patterns of haplotype D but the MORF/MTHIS appeared slightly shorter. Sequence revealed a 35-nt deletion compared with L7261.1 (nucleotides 311 to 345 ).
Eight extracts from Benin and nine from Nigeria were assigned to haplotype $\mathrm{K}$ (M. enterolobii) based on the size and digestion pattern of the TRNA/MRH106 fragment and the lack of an amplification product using the MORF/MTHIS primers. Sequence

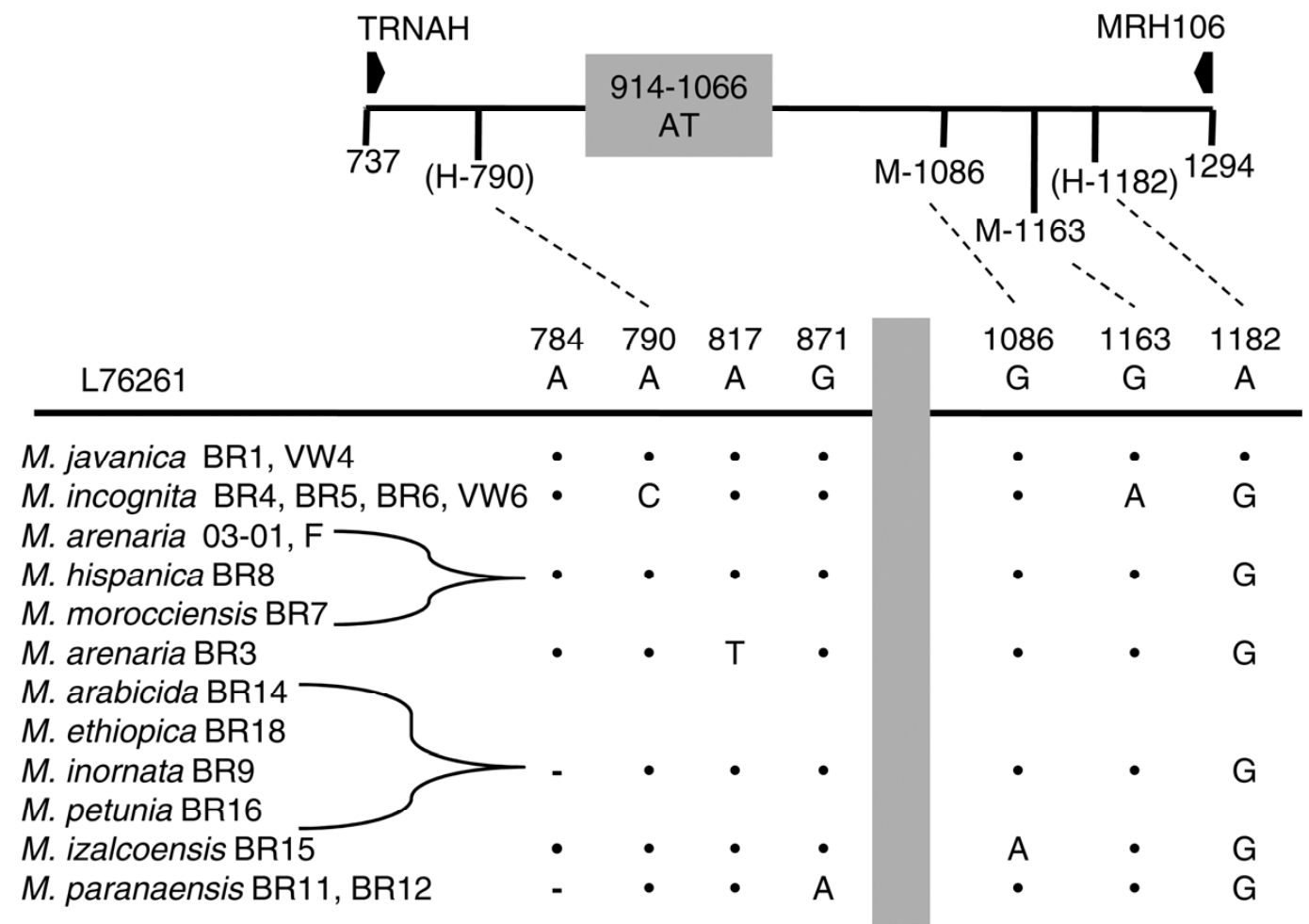

Fig. 3. Sequence polymorphism comparisons of TRNAH/MRH106 amplification products from Meloidogyne incognita group species. The diagram shows the sites of restriction site polymorphisms used to distinguish species. Numbers below fragments refer to positions in $M$. javanica reference sequence (accession number L76261.1). H and M indicate positions of diagnostic cleavage sites for enzymes HinfI and MnlI, respectively. The gray shading shows the position of a stretch of 152-nucleotide sequence that lacks any $\mathrm{G}$ or $\mathrm{C}$ nucleotides. This region was excluded from the sequence comparison. Sites in parentheses are missing in M. javanica but present in other species. Nucleotides that are identical with those of L76261 are indicated by a dot (•); those that differ are indicated by a letter corresponding to the nucleotide; - indicates that a single nucleotide is missing.

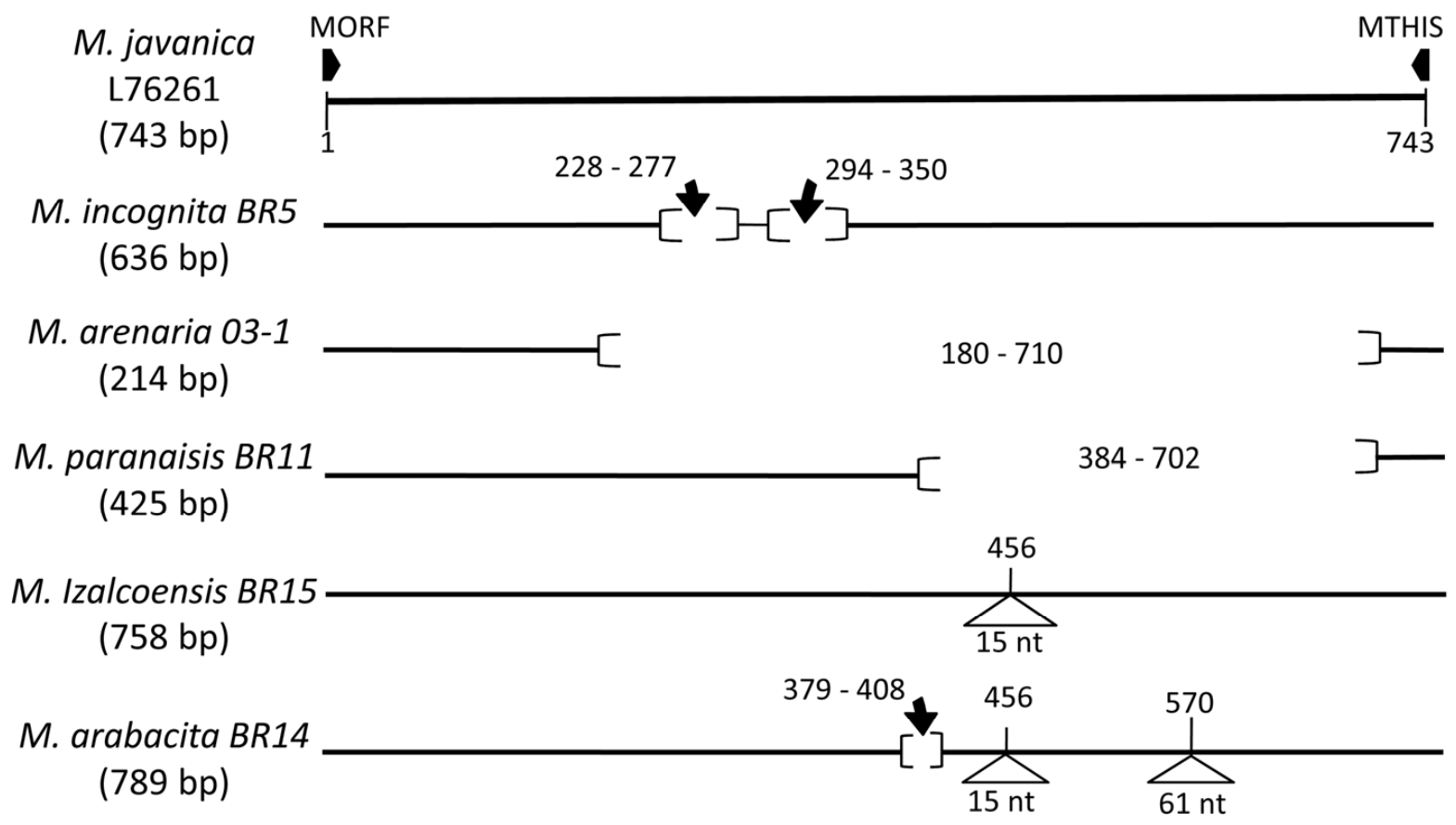

Fig. 4. Comparison of sizes of amplification products spanning the mitochondrial intergenic spacer region of Meloidogyne incognita group root-knot nematode species. The top line represents the reference fragment size amplified from M. javanica reference sequence L76261 using primers MORF/MTHIS. Brackets indicate positions of deletions compared with L76261 and triangles below lines indicate positions and size of insertions. 
analysis of the nine fragments from Nigeria revealed that six were identical and three were $99 \%$ identical to BR17, supporting their identification as M. enterolobii.

\section{DISCUSSION}

This work was stimulated by the need for a simple diagnostic method to identify agriculturally damaging RKNs, especially for tropical regions with limited resources. An important consideration was the ability to utilize DNA extracted from preserved samples and, in this work, we used samples preserved in ethanol to test the assay. We also used primers that would produce a product from a spectrum of species rather than species-specific primers, which we considered important, because prior knowledge of the species present is often lacking. In preliminary experiments, we compared the ability of the mitochondrial primer sets developed by Powers and Harris (39) and by Stanton et al. (46) to amplify samples prepared in various ways and found that the latter primer sets had a higher success rate and better resolved MIG species. Optimization of the assay conditions, most notably lowering the PCR extension temperature to $68^{\circ} \mathrm{C}$, further increased this success rate. The current protocol works well with $\mathrm{J} 2$ and eggs from ethanol-preserved egg masses and produced informative amplification products from all 103 samples from SSA. In other tests, we found that single females dissected from ethanol-preserved root pieces, males, or fresh $\mathrm{J} 2$ produced extracts that amplified well (results not shown). However, Baermann funnel extracts stored in ethanol were not useful because nematode morphology was poorly preserved and $\mathrm{RKN} \mathrm{J} 2$ could not readily be distinguished from other nematodes in the extract.

Previous work (46) assigned haplotypes to the most common species of RKN found in Australian agriculture. To test and extend the utility of the assay, we amplified DNA from a wide range of species from diverse geographical locations, prepared from well-characterized RKN strains, including several strains of the most common species (Table 1). The product produced by the TRNAH/MRH106 primers, which spans part of the mitochondrial 1-rRNA gene and has not been widely used for species identification, was particularly useful. These primers amplified products from all RKN species tested, including more distantly related species $M$. hapla, M. chitwoodi, and M. exigua. In addition, M. enterolobii, which was not previously assessed, was easily dis- tinguished from MIG species and all the other RKN species tested by the distinct fragment size. In agreement with the previous results, $M$. incognita and $M$. javanica gave consistent fragment sizes and cleavage patterns that uniquely defined these two species. However, most other MIG species were not resolved with this primer pair.

Amplification with primers MORF/MTHIS, which flank the nontranscribed spacer, produced a product only for MIG species. Comparison of product sizes resolved some species but also revealed within-species variability for the length of the intergenic spacer, as has been previously noted (5). One isolate of $M$. incognita amplified a slightly smaller MORF/MTHIS fragment (listed as haplotype $\mathrm{B}^{\prime}$ in Table 2). More notably, strains identified as $M$. arenaria fell into two groups based on the size of amplification product with MORF/MTHIS primers. In Table 2, we refer to the strains that amplify a 214-bp fragment (haplotype A) as $M$. arenaria because these appear to have the widest geographic distribution $(5,39,51)$. The remaining strains amplify a 743-bp MORF/MTHIS fragment and can be further subdivided based on the TRNAH/MRH106 pattern. A group of strains from Australia identified as $M$. arenaria produced a TRNAH/MRH106 cleavage pattern not seen for any of the known samples in this study and were classified as haplotype $\mathrm{C} / \mathrm{H}$ (46). We refer to these isolates as $M$. arenaria $\mathrm{V} 1$ and to the isolate described in our study that falls into haplotype $\mathrm{G}$ as $M$. arenaria V2 (Table 2). Within-species differences have previously been noted for isolates of $M$. arenaria in host range and using isozymes, RFLP analysis, PCR markers, and morphological characters $(12,24,27)$, together indicating that this species, as currently defined, encompasses a wider range of diversity than other MIG species.

In spite of intraspecies differences in length, the intergenic region may be useful for resolving some of the species grouped into haplotype G. For example, the MORF/MTHIS fragment of $M$. hispanica BR8 differed in sequence at several positions from $M$. javanica but was identical to the corresponding region in a previous report for $M$. hispanica. MORF/MTHIS fragments amplified from $M$. paranaesis, $M$. izalcoensis, and $M$. arabicida differed in length from $743 \mathrm{bp}$ due to various insertions or deletions compared with M. javanica (Fig. 3), and these differences may be diagnostic. However, we examined only one or two strains of each of these species. Additional isolates should be examined to better determine whether these differences could be

TABLE 2. Mitochondrial haplotype patterns of root-knot nematodes

\begin{tabular}{|c|c|c|c|c|c|c|}
\hline \multirow[b]{2}{*}{ Haplotype } & \multicolumn{3}{|c|}{ TRNAH/MRH106 ${ }^{\mathrm{a}}$} & \multirow[b]{2}{*}{ MORF/MTHIS ${ }^{\mathrm{d}}$} & \multicolumn{2}{|r|}{ Species $^{\mathrm{b}}$} \\
\hline & Uncut & Hinf1 cut & $M n l 1 \mathrm{cut}^{\mathrm{c}}$ & & Stanton et al. & This work \\
\hline A & 557 & 445,112 & $340,140,77$ & 214 & Meloidogyne arenaria & M. arenaria, M. morocciensis \\
\hline B & 557 & $396,112,49$ & 340,217 & 743 & M. incognita & M. incognita \\
\hline $\mathrm{C} / \mathrm{H}$ & 557 & 445,112 & 417,140 & 743 & M. arenaria $\mathrm{V} 1$ & - \\
\hline D & 557 & 557 & $340,140,77$ & 743 & M. javanica & M. javanica \\
\hline G & 557 & 445,112 & $340,140,77$ & 743 & M. hispanica & $\begin{array}{l}\text { M. arenaria } \mathrm{V} 2, \text { M. ethiopica, M. hispanica, } \\
\text { M. inornata, M. petunia }\end{array}$ \\
\hline
\end{tabular}

${ }^{a}$ Fragment sizes vary slightly due to lengths of AT tracts.

${ }^{b}$ V1 or V2 indicate strains with mitochondrial haplotypes different from the most prevalent for that species.

${ }^{c}$ MnlI cleaves DNA at 7 to 8 nucleotides from its recognition site; to reflect this, we have adjusted fragment sizes from those in Stanton et al. (46).

${ }^{\mathrm{d}} \mathrm{NP}=$ no product or weak, nonspecific bands.

TABLE 3. Mitochondrial haplotypes of Africa samples

\begin{tabular}{lcccccccc}
\hline & \multicolumn{7}{c}{ Mitochondrial haplotype } \\
\cline { 3 - 8 } Country & Number of samples & $\mathrm{A}$ & $\mathrm{B}$ & $\mathrm{C} / \mathrm{H}$ & $\mathrm{D}$ & $\mathrm{G}$ & $\mathrm{K}$ \\
\hline Tanzania & 15 & 1 & 3 & 0 & 11 & 0 & 0 \\
Kenya & 15 & 1 & 7 & 0 & 5 & 0 & 0 \\
Nigeria & 50 & 0 & 36 & 0 & 5 & 0 & 2 \\
Benin & 23 & 0 & 7 & 0 & 4 & 3 & 9 \\
\hline
\end{tabular}


used as a diagnostic. Although a considerable resource of sequences spanning the intergenic spacer of various MIG species is available in the public domain, because this region is internal to that amplified by primers developed by Powers and Harris (39), for many of these entries, a species designation is not provided. In cases where species are specified, the criteria used for species assignment are not usually provided, limiting their value in assigning diagnostic characters. Additional diagnostic criteria may be necessary to assign species for some haplotype $G$ samples. For example, species-specific primers have been developed for several haplotype $\mathrm{G}$ species and may be useful for resolution within this group (4).

Our goal here was to identify MIG species and other clade I species such as $M$. enterolobii because these groups are predominant in tropical agriculture. However, three isolates of $M$. hapla, the most prevalent clade II species, and two clade III species, $M$. chitwoodi and M. exigua, were also included in this work. All of these species produce an amplification product with TRNAH/ MRH106 primers but none of the products were digested with $M n l I$, distinguishing them from MIG species and $M$. enterolobii (Table 1). For identification of species outside of the MIG, or for determining the relationship of new species to those that have been characterized, a large resource of $18 \mathrm{~S}$ rDNA sequences is available (26).

Origin and evolution of MIG species. MIG species have been defined by morphological and molecular characters as well as by host range (30). However, because these species reproduce asexually and molecular evidence indicates that they are derived from interspecific hybrids, determining species boundaries is a complex issue. The limited differences between mitochondrial genomes of MIG species supports the theory of a recent separation from a common (or highly related) ancestral mother. Nonetheless, these small differences, especially for the TRNAH/MRH106 fragment, align with species as determined by other criteria, most notably esterase phenotype, and are of diagnostic value. The uniformity of sequence of the mitochondrial region in isolates of the most common species from Australia, Brazil, the United States, and Africa indicates that global dissemination is recent and likely occurred through agricultural practices. Within-species differences in length of the intergenic region indicate that these changes may be more recent and may define separately evolving lineages (Fig. 4). The presence of many species in haplotype $G$ may imply that this group is evolving more rapidly. Alternatively, if, as suggested by Fargette et al. (23) and Hugall et al. (28), diversity is due to ancestral crosses before parthenogenesis, haplotype $G$ species may represent lineages derived from closely related females mating with more diverse males.

What we learned about distribution of RKN in Africa. Each of the 103 samples from SSA that we examined produced mitochondrial haplotypes consistent with MIG species or M. enterolobii, with matches to haplotypes B and $\mathrm{D}$, corresponding to $M$. incognita and $M$. javanica, respectively, highly represented in isolates from all countries. Several West African isolates, based on the TRNAH/MRH106 fragment size, were identified as haplotype K (M. enterolobii) but this haplotype was not observed from East Africa. Two samples from East Africa were of haplotype A (M. arenaria), which was not identified in West Africa. Only three samples, all from Benin, were a match for haplotype G. These haplotype $G$ samples and the three novel haplotypes identified from Kenya and Benin will require further attention to identify.

Because we have examined only one egg mass per isolate from a limited range of locations and hosts, our work should be considered a proof of concept rather than a comprehensive description of species present in these countries. Greater depth of assessment, including using several egg masses from each locale to detect mixed populations, would provide a more thorough picture. However, our findings are consistent with the range of species presented in other reports from SSA $(3,5,23)$. Altogether, our study indicates that the mitochondrial haplotype approach is a useful and straightforward first step to assess the range and variability of clade I RKN species in areas that have not yet been well surveyed.

\section{ACKNOWLEDGMENTS}

This work was supported by an IITA/USAID Linkage Grant to D. L. Coyne and V. M. Williamson and by a University of California ANR competitive grant to V. M. Williamson. We thank G. Bruening for key suggestions on PCR conditions and S. Subbotin for helpful comments on the manuscript.

\section{LITERATURE CITED}

1. Abad, P., Gouzy, J., Aury, J.-M., Castagnone-Sereno, P., Danchin, E. G. J., Deleury, E., Perfus-Barbeoch, L., Anthouard, V., Artiguenave, F., Blok, V. C., Caillaud, M. C., Coutinho, P. M., Dasilva, C., De Luca, F., Deau, F., Esquibet, M., Flutre, T., Goldstone, J. V., Hamamouch, N., Hewezi, T., Jaillon, O., Jubin, C., Leonetti, P., Magliano, M., Maier, T. R., Markov, G. V., McVeigh, P., Pesole, G., Poulain, J., Robinson-Rechavi, M., Sallet, E., Ségurens, B., Steinbach, D., Tytgat, T., Ugarte, E., van Ghelder, C., Veronico, P., Baum, T. J., Blaxter, M., Bleve-Zacheo, T., Davis, E. L., Ewbank, J. J., Favery, B., Grenier, E., Henrissat, B., Jones, J. T., Laudet, V., Maule, A. G., Quesneville, H., Rosso, M. N., Schiex, T., Smant, G., Weissenbach, J., and Wincker, P. 2008. Genome sequence of the metazoan plant-parasitic nematode Meloidogyne incognita. Nat. Biotechnol. 26:909-915.

2. Adam, M. A. M., Phillips, M. S., and Blok, V. C. 2007. Molecular diagnostic key for identification of single juveniles of seven common and economically important species of root-knot nematode (Meloidogyne spp.). Plant Pathol. 56:190-197.

3. Birithia, R., Waceke, W., Loino, P., and Masiga, D. 2012. Identification of root-knot nematode species occurring on tomatoes in Kenya: Use of isozyme phenotypes and PCR-RFLP. Int. J. Trop. Insect Sci. 32:78-84.

4. Blok, V. C., and Powers, T. O. 2009. Biochemical and molecular identification. Pages 98-118 in: Root-knot Nematodes. R.N. Perry, M. Moens, and J. Starr, eds. CABI Publishing, UK.

5. Blok, V. C., Wishart, J., Fargette, M., Berthier, K., and Phillips, M. S. 2002. Mitochondrial DNA differences distinguishing Meloidogyne mayaguensis from the major species of tropical root-knot nematodes. Nematology 4:773-781.

6. Bridge, J., Coyne, D., and Kwoseh, C. K. 2005. Nematode parasites of tropical root and tuber crops. Pages 221-258 in: Plant Parasitic Nematodes in Subtropical and Tropical Agriculture, Revised 2nd ed. M. Luc, R. Sikora, and J. Bridge, eds. CAB International, UK.

7. Carneiro, R., Tigano, M. S., Randig, O., Almeida, M., and Sarah, J.-L. 2004. Identification and genetic diversity of Meloidogyne spp. (Tylenchida: Meloidogynidae) on coffee from Brazil, Central America and Hawaii. Nematology 6:287-298.

8. Carneiro, R. M. D. G., and Almeida, M. R. A. 2001. Técnica de eletroforese usada no estudo de enzimas dos nematóides de galhas para identificação de espécies. Nematol. Bras. 25:35-44.

9. Carneiro, R. M. D. G., Almeida, M. R. A., and Gomes, M. C. B. 2004. Primeiro registro de Meloidogyne hispanica Hirchmann, $1986 \mathrm{em}$ abóbora no estado da Bahia, Brasil. Nematol. Bras. 28:215-218.

10. Carneiro, R. M. D. G., Almeida, M. R. A., Gomes, A. C. M., and Hernandez, A. 2005. Meloidogyne izalcoensis n. sp. (Nemata: Meloidogynidae), a root-knot nematode parasitising coffee in El Salvador. Nematology 7:819-832.

11. Carneiro, R. M. D. G., Almeida, M. R. A., and Quénéhervé, P. 2000. Enzyme phenotypes of Meloidogyne spp. isolates. Nematology 2:645654.

12. Carneiro, R. M. D. G, dos Santos, M. F. A., Almeida, M. R. A., Mota, F. C., Gomes, A. C. M. M., and Tigano, M. S. 2008. Diversity of Meloidogyne arenaria using morphological, cytological and molecular approaches. Nematology 10:819-834.

13. Carneiro, R. M. D. G., Mendes, M. L., Almeida, M. R. A., and Karssen, G. 2008. Additional information on Meloidogyne inornata Lordello, 1956 (Tylenchida: Meloidogynidae) and its characterisation as a valid species. Nematology 10:123-136.

14. Carneiro, R. M. D. G., Randig, O., Almeida, M. R. A., and Gomes, A. C. M. 2004. Additional information on Meloidogyne ethiopica Whitehead, 1968 (Tylenchida: Meloidogynidae) a root-knot nematode parasitising kiwi-fruits and grapevine from Brazil and Chile. Nematology 6:109-123.

15. Castagnone-Sereno, P. 2012. Meloidogyne enterolobii (=M. mayaguensis): Profile of an emerging, highly pathogenic, root-knot nematode species. Nematology 14:133-138. 
16. Castro, J. M. C., Lima, R. D., and Carneiro, R. M. D. G. 2003. Variabilidade isoenzimática de populações de Meloidogyne spp. de regiões brasileiras produtoras de soja. Nematol. Bras. 27:1-12

17. Charchar, J. M. Eisenback, J. D and Hirschmann, H. 1999. Meloidogyne petuniae $\mathrm{n}$. sp. (Nemata: Meloidogynidae), a root-knot nematode parasitic on petunia in Brazil. J. Nematol. 31:81-91.

18. Correa, V. R., Mattos, V. S., Almeida, M. R. A., Santos, M., Tigano, M. S., Castagnone-Sereno, P., and Carneiro, R. M. D. G. 2014. Genetic diversity of the root-knot nematode Meloidogyne ethiopica and development of a species-specific SCAR marker for its diagnosis. Plant Pathol. 63:476-483.

19. Correa, V. R., Santos, M. F. A., Almeida, M. R. A., Peixoto, J. R., Castagnone-Sereno, P., and Carneiro, R. M. D. G. 2013. Species-specific DNA markers for identification of two root-knot nematodes of coffee: Meloidogyne arabicida and M. izalcoensis. Eur. J. Plant Pathol. 137:305-313.

20. Coyne, D. L., Fourie, D., and Moens, M. 2009. Current and future management strategies in resource-poor regions. Pages 444-475 in: Rootknot Nematodes. R. N. Perry, M. Moens, and J. Starr, eds. CABI Publishing, UK.

21. De Waele, D., and Elsen, A. 2007. Challenges in tropical plant nematology. Annu. Rev. Phytopathol. 45:457-485.

22. Esbensade, P. R., and Triantaphyllou, A. C. 1990. Isozyme phenotypes for the identification of Meloidogyne species. J. Nematol. 22:10-15.

23. Fargette, M., Berthier, K., Richaud, M., Lollier, V., Franck, P., Hernandez, A., and Frutos, R. 2010. Crosses prior to parthenogenesis explain the current genetic diversity of tropical plant-parasitic Meloidogyne species (Nematoda: Tylenchida). Infect. Genet. Evol. 10:807-814.

24. Fargette, M., Phillips, M. S., Blok, V. C., Waugh, R., and Trudgill, D. C. 1996. An RFLP study of relationships between species, isolates and resistance-breaking lines of tropical species of Meloidogyne. Fundam. Appl. Nematol. 19:193-200.

25. Gissi, C., Iannelli, F., and Pesole, G. 2008. Evolution of the mitochondrial genome of metazoa as exemplified by comparison of congeneric species. Heredity 101:301-320.

26. Holterman, M., Karssen, G., van den Elsen, S., van Megen, H., Bakker, J., and Helder, J. 2009. Small subunit rDNA-based phylogeny of the Tylenchida sheds light on relationships among some high-impact plantparasitic nematodes and the evolution of plant feeding. Phytopathology 99:227-235.

27. Hugall, A., Moritz, C., Stanton, J., and Wolstenholme, D. R. 1994. Low, but strongly structured mitochondrial DNA diversity in root-knot nematodes (Meloiodgyne). Genetics 136:903-912.

28. Hugall, A., Stanton, J., and Moritz, C. 1999. Reticulate evolution and the origins of ribosomal internal transcribed spacer diversity in apomictic Meloidogyne. Mol. Biol. Evol. 16:157-164.

29. Humphreys, D. A., Williamson, V. M., Salazar, L., Florese-Chaves, L., and Gomez-Alpizar, L. 2012. Presence of Meloidogyne enterolobii Yang\& Eisenback (= M. mayaguensis) in guava and acerola from Costa Rica. Nematology 14:199-207.

30. Hunt, D. J., and Handoo, Z. A. 2009. Taxonomy, identification and principal species. Pages 55-97 in: Root-knot Nematodes. R. N. Perry, M. Moens, and J. Starr, eds. CABI Publishing, UK.

31. Liu, Q. L., and Williamson, V. M. 2006. Host-specific pathogenicity and genome differences between inbred strains of Meloidogyne hapla. J. Nematol. 38:158-164.

32. Luc, M., Sikora, R., and Bridge, J. 2005. Plant Parasitic Nematodes in Subtropical and Tropical Agriculture, Revised 2nd ed. CAB International, UK.

33. Lunt, D. H. 2008. Genetic tests of ancient asexuality in root knot nematodes reveal recent hybrid origins. BMC Evol. Biol. 8:194.

34. Lunt, D. H., Kumar, S., Koutsovoulos, G., and Blaxter, M. L. 2014. The complex hybrid origins of the root knot nematodes revealed through comparative genomics. PeerJ 2:e356. doi: 10.7717/peerj.356

35. Moens, M., Perry, R. N., and Starr, J. L. 2009. Meloidogyne species-A diverse group of novel and important plant parasites. Pages 1-17 in: Rootknot Nematodes. R. N. Perry, M. Moens, and J. Starr, eds. CABI Publishing, UK.
36. Mojtahedi, H., Santo, G. S., and Wilson, J. H. 1988. Host tests to differentiate Meloidogyne chitwoodi races 1 and 2 and M. hapla. J. Nematol. 20:468-473

37. Muniz, M. F., Campos, V. P., Castagnone-Sereno, P., Castro, J. M. C., Almeida, M. R. A., and Carneiro, R. M. D. G. 2008. Diversity of Meloidogyne exigua (Tylenchida: Meloidogynidae) populations from coffee and rubber tree. Nematology 10:897-910.

38. Onkendi, E. M., Kariuki, G. M., Marais, M., and Moleleki, L. N. 2014. The threat of root-knot nematodes (Meloidogyne spp.) in Africa: A review. Plant Pathol. 63:727-737.

39. Powers, T. O., and Harris, T. S. 1993. A polymerase chain reaction method for identification of five major Meloidogyne spp. J. Nematol. 25:1-6.

40. Powers, T. O., Platzer, E. G., and Hyman, B. C. 1986. Species-specific restriction site polymorphism in root-knot nematode mitochondrial DNA. J. Nematol. 18:288-293.

41. Qiu, J. J., Westerdahl, B. B., Anderson, C., and Williamson, V. M. 2006. Sensitive PCR detection of Meloidogyne arenaria, $M$. incognita, and $M$. javanica extracted from soil. J. Nematol. 38:434-441.

42. Randig, O., Bonglovanni, M., Carneiro, R. M. C. G., and CastagnoneSereno, P. 2002. Genetic diversity of root-knot nematodes from Brazil and development of SCAR markers specific for the coffee-damaging species. Genome 45:862-870.

43. Sasser, J. N., Eisenback, J. D., Carter, C. C., and Triantaphyllou, A. C. 1983. The international Meloidogyne project, its goals and accomplishments. Annu. Rev. Phytopathol. 21:271-288.

44. Silva, E. H., Mattos, V. S., Furlaneto, C., Giband, M., Barroso, P. A. V., Moita, A. W., Jorge-Junior, A., Correa, V. R., Castagnone-Sereno, P., and Carneiro, R. M. D. G. 2014. Genetic variability and virulence of Meloidogyne incognita populations from Brazil to resistant cotton genotypes. Eur. J. Plant Pathol. 139:195-204.

45. Silva, J. G. P., Furlanetto, C., Almeida, M. R. A., Rocha, D. B., Mattos, V. S., Correa, V. R., and Carneiro, R. M. D. G. 2014. Occurrence of Meloidogyne spp. in Cerrado vegetations and reaction of native plants to Meloidogyne javanica. J. Phytopathol. 162:449-455.

46. Stanton, J., Hugall, A., and Moritz, C. 1997. Nucleotide polymorphisms and an improved PCR-based mtDNA diagnostic for parthenogenetic rootknot nematodes (Meloidogyne spp.). Fundam. Appl. Nematol. 20:261268.

47. Tigano, M., Siqueira, K., Castagnone-Sereno, P., Mulet, K., Queiroz, P., Santos, M., Teixeira, C., Almeida, M., Silva, J., and Carneiro, R. 2010. Genetic diversity of the root-knot nematode Meloidogyne enterolobii and development of a SCAR marker for this guava-damaging species. Plant Pathol. 59:1054-1061.

48. Tigano, M. S., Carneiro, M. D. G., Jeyaprakash, A., Dickson, D. W., and Adams, B. J. 2005. Phylogeny of Meloidogyne spp. based on 18S rDNA and the intergenic region of mitochondrial DNA sequences. Nematology 7:851-862.

49. Trudgill, D. L., and Blok, V. C. 2001. Apomictic, polyphagous root-knot nematodes: Exceptionally successful and damaging biotophic root pathogens. Annu. Rev. Phytopathol. 39:53-77.

50. Wang, C., Bruening, G., and Williamson, V. M. 2009. Determination of preferred $\mathrm{pH}$ for root-knot nematode aggregation using pluronic F-127 gel. J. Chem. Ecol. 35:1242-1251

51. Xu, J., Liu, P., Meng, Q., and H. Long. 2004. Characterization of Meloidogyne species from China using isozyme phenotypes and amplified mitochondrial DNA restriction fragment length polymorphism. Eur. J. Plant Pathol. 110:309-315.

52. Yaghoobi, J., Kaloshian, I., Wen, Y., and Williamson, V. M. 1995. Mapping a new nematode resistance locus in Lycopersicon peruvianum. Theor. Appl. Genet. 91:457-464

53. Zijlstra, C., Donkers-Venne, D. T. H. M., and Fargette, M. 2000. Identification of Meloidogyne incognita, M. javanica and M. arenaria using sequence characterised amplified region (SCAR) based PCR assays. Nematology 2:847-845.

\section{Erratum}

The labeling on Figure 2A, B, and $\mathrm{C}$ has been corrected to read Mj VW4 and Mi VW6. Changes to this article were made on 4 March 2015. 